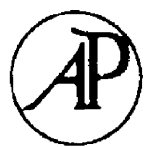

ELSEVIER

\title{
Notification and awareness: synchronizing task-oriented collaborative activity
}

\author{
John M. Carroll*, Dennis C. Neale, Philip L. Isenhour, \\ Mary Beth Rosson, D. Scott McCrickard \\ Center for Human-Computer Interaction, Department of Computer Science, Virginia Tech, \\ Blacksburg, VA 24061-0106, USA
}

Received 1 May 2002; accepted 1 November 2002

\begin{abstract}
People working collaboratively must establish and maintain awareness of one another's intentions, actions and results. Notification systems typically support awareness of the presence, tasks and actions of collaborators, but they do not adequately support awareness of persistent and complex activities. We analysed awareness breakdowns in use of our Virtual School system - stemming from problems related to the collaborative situation, group, task and tool support - to motivate the concept of activity awareness. Activity awareness builds on prior conceptions of social and action awareness, but emphasizes the importance of activity context factors like planning and coordination. This work suggests design strategies for notification systems to better support collaborative activity.
\end{abstract}

(C) 2003 Elsevier Science Ltd. All rights reserved.

Keywords: Activity awareness; Awareness; Awareness breakdowns; Collaboration; Computer-Supported Collaborative Learning (CSCL); Computer-Supported Collaborative Work (CSCW); Notification systems

\section{Introduction}

In order to collaborate effectively one needs to know many things about one's collaborators: Who are they? What do they know? What do they expect? What do they want to do? What are they doing now? What tools are they using? To what other resources do they have access? What are they thinking about? What are they

*Corresponding author. Tel.: + 1-540-231-8453; fax: 1-703-231-6075.

E-mail address: carroll@cs.vt.edu (J.M. Carroll). 
planning to do in the near future? What criteria will they use to evaluate joint outcomes?

In ordinary face-to-face communication, people work to establish and maintain a shared background of understanding called common ground (Clark, 1996). Conversational interaction involves continual testing for evidence of common ground, and coordinated effort to enhance common ground. For example, if an interlocutor fails to respond to a request, one might restate presupposed information, point to a relevant object, request acknowledgement or otherwise remediate. Common ground is unproblematic in face-to-face interactions because such a wide variety of situational elements contribute to it, and the work that people do to maintain common ground is so well integrated into habits and conventions of interaction.

When people work collaboratively, but not face-to-face, many interaction resources are disrupted (Tang, 1991): field of view is reduced, the possibility to use gesture is limited, facial expressions are eliminated or constrained, auditory cues are diminished, tools and artefacts cannot be as easily shared, deixis and spatial coreferences are difficult to resolve, exchanged information is delayed or decoupled by seconds or even minutes, and collaborators may be in different time zones or different cultures. In remote collaboration it is difficult to convey or discern successful comprehension, current focus of attention or concomitant attitudes and affect. It is difficult to repair or remediate miscommunications. This transforms the maintenance of common ground into a significant task, which is itself problematic: people are accustomed to taking common ground for granted, as a background task. They do not want to spend attention and effort on it. They often do not notice when common ground is lacking or inadequate. All this makes for an especially difficult interface design challenge.

Our primary goal in this paper is to investigate the role of notification systems in supporting collaborative awareness. Notification systems are typically lightweight, event-triggered displays of information peripheral to a person's current task-oriented concern, for example, system status updates, email alerts, stock tickers and chat messaging. They animate and enrich the display areas outside the primary application window(s), and help to keep people aware of events beyond their current task-oriented interactions. In many cases, notifications support collaborative awareness, for example, in signaling the arrival of an email from a collaborator, but signaling isolated events does not adequately support awareness of complex and ongoing collaborative activities. Examining the current and future role of notification systems in supporting collaborative awareness would help to clarify what notification systems are and what they are not. This will help to guide possible alternative trajectories for developing the concepts of notifications and notification systems.

Activity awareness is the awareness of project work that supports group performance in complex tasks. Activities are long-term endeavors directed at major goals like planning the layout of a town park. We adopt this terminology from activity theory (e.g. Bodker, 1996; Bardram, 1998). Significant activity entails topdown goal decomposition, nonlinear development of partially ordered plan 
fragments, interleaving of planning, acting and evaluation and opportunistic plan revision. It involves coordinating and carrying out different types of task components, such as assigning roles, making decisions, negotiating, prioritizing and so forth. We found that in the design of notification systems, these components must be understood and pursued in the context of the overall purpose of a shared activity, the goals and requirements for completing it and the relationship of individual tasks to the group's overall plan.

Our work on activity awareness raises many issues in the design of user interfaces for computer-supported collaboration. We begin by describing the Virtual School, a system that supports remote collaboration in an educational setting; the Virtual School used several notification mechanisms to promote common ground and awareness. When we evaluated the system in a classroom setting, we observed a number of breakdowns related to activity awareness. After first reviewing related work on collaborative awareness - emphasizing awareness of social and action information - we provide a detailed analysis of these awareness breakdowns. This analysis has led to the design of new notification tools in our collaborative system, as well as to general design strategies that we believe may be appropriate for other notification systems supporting collaborative work.

\section{Enhancing collaboration with notification systems}

We have developed notification tools as part of our Learning in Networked Communities (LiNC) project (Isenhour et al., 2000; Carroll et al., 2000a). The LiNC project was a multi-year effort to develop and study the use of network-based software tools and applications in middle and high school science classrooms.

We developed a Java-based collaborative learning environment called the Virtual School. The system was developed as part of a long-term participatory design effort between researchers and a group of public school teachers (Carroll et al., 2000b). We worked closely with teachers and students to specify and develop the software, which supports and coordinates a variety of synchronous and asynchronous interactions. The system was designed to structure collaborative learning by providing relevant tools and a variety information about student's activities in the software. However, we did not try to manage the learning process itself (Jermann et al., 2002). Our participatory design efforts were oriented to supporting teachers' learning objectives and classroom practices.

The central tool in the Virtual School is a collaborative editor employing the metaphor of a "science notebook." Students use the notebook to build, organize and share projects and experiments. The notebook has several kinds of specialized pages - a planning tool for organizing roles and tasks, a bibliography tool for helping students build reference lists to be included in reports, a shared whiteboard for generating and annotating graphics, and of course text/graphics pages for creating and editing the body of reports. Collaborative use of the notebook is supported by a set of communication mechanisms, including video conferencing, text chat and email. Fig. 1 shows one side of a collaborative interaction in the Virtual 


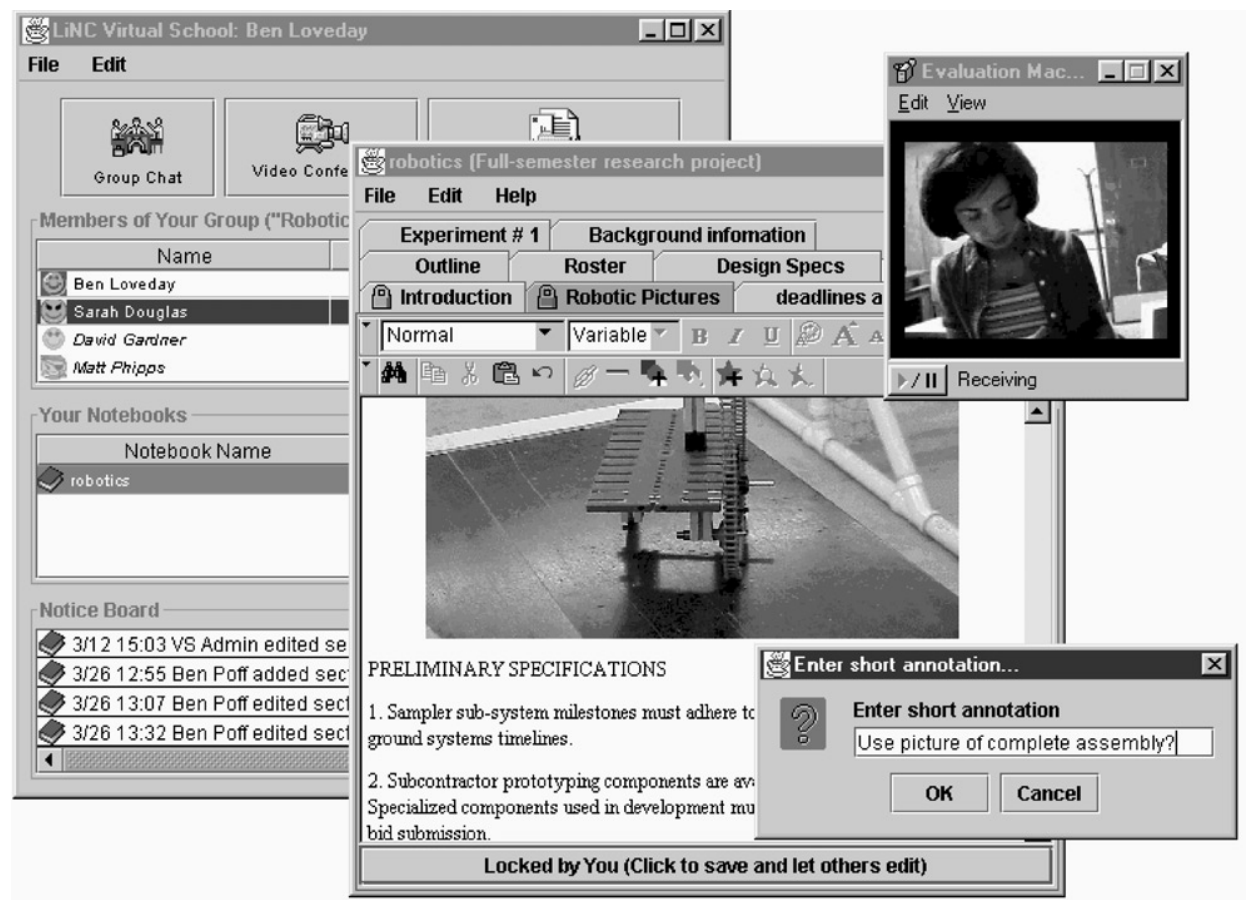

Fig. 1. Collaboration and awareness tools in the Virtual School.

School. The notebook is the central window in the figure; it is currently displaying a collection of robot pictures on a text-graphics notebook page.

Awareness of collaborators' presence, actions and contributions to collaborative activity is supported in a variety of ways in this system. The session manager window, in the upper left of Fig. 1, displays three sorts of status information, a roster of team members, a list of current notebooks and a notice board. The roster pane indicates group affiliations and current presence, location and activity in the system (activity in terms of current idle time). Auditory cues notify users when people leave or join the session. The list of notebooks indicates when shared notebooks were last edited. The notice board presents a permanent notification log of significant user actions, such as editing and creating notebook pages.

The notebook itself also supports awareness in several ways. Planner pages in the notebook provide Gantt chart views of project state, task descriptions, deadlines and completed tasks. These tools provide coordination mechanisms for managing dependencies between activities (Malone and Crowston, 2001). All pages can be annotated to cue collaborators about facets of an activity or to make general comments (an annotation dialog is shown in Fig. 1). The granularity of collaborative editing in the notebook is the page, green and red lock icons (in the tabbed page navigation controls in Fig. 1) indicate what pages are currently under a user's editing control, or being edited by a collaborator. A "show author" feature displays text 
contributions of different authors within a given page in different colors. Awareness among collaborators is also maintained by explicit communication and coordination actions, such as sending email or participating in chat interactions and video conferences. The Virtual School functionality described above was developed iteratively over several years using participatory design with teachers and students. Five different teachers, hundreds of students and a variety of projects contributed to the requirements that led to our current design.

Middle school physical science and high school physics classes carried out a variety of group projects and science experiments using the Virtual School. Small groups of 2-5 students worked proximally as part of a larger distributed team involving 2-4 mutually remote school sites. The Virtual School enabled a variety of stimulating and productive collaborative activities involving within-grade-level and cross-grade-level student groups dispersed at different school sites, mentoring interactions with community science experts, and collaborative professional relationships among the participating teachers (Gibson et al., 1999; Carroll et al., 2000b; Dunlap et al., 2000). However, despite the various awareness mechanisms and notifications used to support students' collaborative work, breakdowns in collaborative work frequently occurred. These problems typically reflected the complexity involved in maintaining awareness of long-term activities distributed among different sites.

\subsection{Assessing notification breakdowns in the Virtual School}

We used breakdown analysis to analyse the usage data from a typical classroom project, 26 weeks in duration (Neale et al., in preparation). A breakdown is a problem in system use that interrupts a person's activity, making him or her more conscious of the system, and less able to focus on what the activity the system is supporting (Winograd and Flores, 1986). Breakdowns force users to engage in problem diagnosis and decomposition in response to the difficulty. We follow Bardram (1998) and Hartswood and Procter (2000) in using breakdowns to analyse group activity and the use of computer-supported cooperative work (CSCW) systems. Note that "collaborative breakdowns" are often distributed: they may involve multiple inter-related problems experienced differently by different collaborators, and they may require a combination of actions taken by multiple agents to diagnose and repair.

A rich array of field data (user action logs, field notes, transcribed video records) were organized into integrated event logs (Neale and Carroll, 1999); these integrated records are critical for reconstructing synchronous interactions of groups distributed across different classroom locations. Our analysis is based on a total of $26 \mathrm{~h}$ of synchronous interaction, which were complemented by comments and discussions collected via our collaborative critical incident tool (Neale et al., 2000). The tool allows evaluators, developers and teachers to share, evaluate and discuss incidents observed in the field. Fifteen critical incidents were reported and discussed over a 2-month period. This overall data aggregation provided a rich picture of Virtual School user activity. 
The specific science project examined included two groups of students - one composed of middle school students and one of high school students - who studied and applied principles of aerodynamics by building and testing kite models with different structural properties. Aside from a requirement to generate a final report, the project was relatively open-ended. Synchronous collaboration sessions were typically no longer than $30 \mathrm{~min}$, and the students used video conferencing and chat to communicate while developing content in the collaborative notebook. Student teams were given little specific guidance as to how to collaborate with their remote partners beyond "complete the project together." None of the students had previously worked in distributed teams or used collaborative software.

The breakdowns we observed (discussed in detail in Section 4) suggest that the notification tools of the Virtual School did not always effectively support collaborative awareness. We identified many problems that seemed to stem from the relative salience of students' local task, classroom situation and social relationships, compared to their awareness of remote collaborators and activities. Over time, and through the course of activity, the remote collaborators and their activities seemed to slip in and out of view.

\section{Refining the awareness concept}

One of the challenges in supporting collaborative awareness is that users need to establish and maintain a "background" understanding of information that may not be directly related to the task currently in focus. Rarely is awareness the sole or even primary task of an individual; nonetheless, awareness of what and how collaborators are contributing to a task may influence a person's immediate efforts, or suggest changes to tasks that may improve overall productivity. The relevant information may be relatively short-term and isolated (e.g. parts of a document that have just been edited), or it may be quite extensive with many interconnected elements (e.g. the current status of a project plan spanning weeks or months).

Researchers have studied the problems of awareness in situations where people construct shared products in real time (e.g. using a shared workspace; Gutwin \& Greenberg), in collaborations that extend across time (e.g. document co-authoring; Neuwirth et al., 1998), and in work situations with well-established dependencies (e.g. project workflow; Prinz and Kolvenbach, 1996). We examine these awareness issues as a research topic in CSCW. Throughout, we point to the role that notification systems have in promoting collaborative awareness.

\subsection{Social awareness}

Early work on awareness focused on people's understanding of the current social context in remote collaborations: who is here, who can I work with? Some organizations explored the use of open video links between remote offices (Mantei et al., 1991; Olson and Bly, 1991; Dourish and Bly, 1992; Fish et al., 1993; Tang et al., 1994; Dourish et al., 1996). The periodic updates provided by these links promoted 
incidental awareness of changes in team members' presence and activity level, copresent others, the facial expressions of current or potential collaborators, and so on (Fig. 2). Such information simulates the background information that one obtains in co-located groups by looking and listening as one walks by offices and common rooms, and facilitates ad hoc communication and collaboration. Ironically, highquality video links can distract people from primary tasks and undermine their performance (Tang and Isaacs, 1993; Masoodian et al., 1995). In general, the benefits of video links are limited, and most of the early systems have been abandoned (Egido, 1988; Angiolillo et al., 1993; Olson and Olson, 2002).

Recent work has explored more lightweight representations for maintaining social awareness in remote collaborations. A "chat circle" displays participants in a chat room, as well as visualizing their contributions over time (Viegas and Donath, 1999). Similarly, the Babble system (Erickson et al., 1999) includes a "social proxy" showing team members' level of contribution to a threaded discussion. Other researchers have explored the use of icons or other simple visual depictions to convey information about the status of individuals at a remote site (Greenberg, 1996; Cadiz et al., 2001; Tang et al., 2001). These notification systems provide information about changes in the social milieu-as an interaction progresses, users are notified of collaborators' arrival, availability for interaction, involvement and departure.

Studies of social awareness emphasize that it is just one facet of the awareness problem, necessary but not sufficient for establishing effective common ground over longer periods and across diverse activities (Buxton et al., 1997). Indeed, when collaborators can choose, they often use video channels to share data and other work-related artefacts, rather than as a channel for observing one another (Endsley, 1995; Hall et al., 1996; Whittaker and O'Conaill, 1997). Thus, most current research is focused on how to support awareness of planning, acting and task status against a background of social awareness (Gutwin et al., 1996; Dourish et al., 1999; Gutwin and Greenberg, 1996, 1998a, b, 2000; Carroll et al., 2001; Isenhour et al., 2000).

\subsection{Action awareness}

In many remote collaboration situations, team members access and manipulate shared resources (e.g. documents, images, databases). In these cases it is not sufficient to know who is around, and whether they are available for interaction.

\begin{tabular}{|l|l|}
\hline \multicolumn{1}{|c|}{ Awareness concern } & \multicolumn{1}{c|}{ Information needed to address this awareness concern } \\
\hline $\begin{array}{l}\text { Social: "Who is } \\
\text { around?" }\end{array}$ & $\begin{array}{l}\text { Presence of collaborators; features of an online collaborator that convey motivational } \\
\text { state or attitude; timing, frequency, or intensity of individual or group activity or } \\
\text { communication }\end{array}$ \\
\hline $\begin{array}{l}\text { Action: "What is } \\
\text { happening?" }\end{array}$ & $\begin{array}{l}\text { Timing, type, or frequency of collaborators' interactions with a shared resource; } \\
\text { location and focus of collaborators' current activity }\end{array}$ \\
\hline $\begin{array}{l}\text { Activity: "How are } \\
\text { things going?" }\end{array}$ & $\begin{array}{l}\text { Creation or changes to shared plans, evaluations, or rationale; assignment or } \\
\text { modifications of project roles; task dependencies based on roles, timing, resources, } \\
\text { etc.; exception handling }\end{array}$ \\
\hline
\end{tabular}

Fig. 2. Three awareness concerns and information that might address them. 
Users need notification systems that keep them informed about what is happening to objects they care about - what actions are being taken to investigate or modify them, and who is carrying out such actions (Fig. 2). The relevant information may be a discrete event (e.g. selection of a document), or it may be a snap shot that aggregates an extended series of events (e.g. extracting and presenting the gist of a series of changes to a shared document, Neuwirth et al., 1998).

A large body of work on action awareness has studied the problems of synchronous collaboration in shared workspaces (Gutwin et al., 1996; Smith et al., 1998). A successful and early example is the radar view, a miniaturized workspace overview that uses rectangular outlines to indicate the part of the workspace in view for different collaborators (Smith, 1992; Beacker et al., 1993; Gutwin and Greenberg, 1996). Radar views provide information about the presence and location of collaborators in a workspace (social awareness), but also provide information about other users' interactions with workspace objects (action awareness). Telepointers (individual pointers for each remote collaborator) can also be used to convey collaborators' focus and gestures (e.g. pointing at a document during discussion). Other researchers have explored techniques that superimpose video information conveying work partners' gaze on top of a shared workspace containing task objects (Ishii et al., 1994). An important issue for action awareness is the tradeoff between the amount of information provided, and users' ability to comprehend and use it (Begole et al., 1999).

Many collaborations with shared resources take place over time. Although moment-to-moment awareness is less of a concern in this case (e.g. collaborators are not competing for a resource), knowing what has happened recently to an object, and who is responsible, may influence one's own decisions about what to do. Version control systems support an extended awareness of actions, by maintaining a history of shared resources, perhaps even providing facilities for visualizing what has changed (Hawryszkiewyez et al., 1995; Fussell et al., 1998). Hill et al. (1992) introduced the concepts of "read wear" and "edit wear" as mechanisms for tracking access or modifications to objects over time (e.g. paragraphs of a document that are viewed or edited, columns of a spreadsheet that have been changed). Researchers have also explored techniques for visualizing the history of interactions with web pages (Wexelblat and Maes, 1999; Chi et al., 2001) or objects in a shared workspace (Gutwin, 2002). For the most part, however, there has been a disconnect between work supporting awareness in real time situations and the capture, integration and presentation of interactions over an extended period of time (Carroll et al., 2001).

Knowing what actions collaborators have taken helps users to keep track of the state of task-relevant objects, and to monitor collaborators' contributions. However, it is up to the individual to provide an interpretive frame for this information, to determine when the information is relevant or how it is related to current task goals. As with social awareness, this extra requirement often results in user interactions where awareness maintenance is managed as a separate task-namely a task of coordination that is imposed on top of the real task of creating a shared document, reaching consensus on a shared vision and so on. 


\subsection{Activity awareness}

The social exchange and actions of a work group are situated in a rich context of organizational strategies and objectives, job roles and responsibilities, interpersonal relationships, task assignments and interdependencies and tool-handling and material resources. This context is the domain of activities-long-term joint endeavors directed at major goals like writing an NSF proposal (Bodker, 1996; Bardram, 1998). Social awareness simply indicates presence information, and action awareness describes progress in isolated tasks. However, issues in collaborative systems transcend these basic cues. Needs and problems that we were unable to describe in the rubric of social and action awareness become clear through the lens of activity awareness - we can extend the value of social and action awareness by providing them as part of an activity context that promotes informed action and reaction. In the Virtual School, collaborators needed notifications to support social and action awareness, but they needed more. They also needed awareness of the overall situation, the social expectations and dependencies within their group, and their shared task goals and status.

The situation in which collaborations take place provides an overarching framework for setting goals, coordinating efforts and evaluation progress. Every organization has strategies and objectives, expectations and standard procedures that guide the projects it sponsors. In the Virtual School, the collaborators were students in eighth and 12th grade science classes; the classes were themselves embedded in a middle school and a high school, respectively, and overseen by teachers from those schools. These institutional structures, roles and relationships define the school science situation. High school science teachers have rather different expectations and standards than their middle school counterparts.

The concept of activity awareness subsumes situation awareness, defined informally as "knowing what is going on around you" (Endsley, 2000), or more precisely "the perception of the elements in the environment within a volume of time and space, the comprehension of their meaning and the projection of their status in the near future" (Endsley, 1988). Situation awareness has been analysed for tasks that require integration of complex and dynamic multi-sensory information arrays. Perception, information processing, decision-making, memory, learning and performance of actions have important consequences for situation awareness (Blanchard, 1993). Such concerns play a role in activity awareness as well (certainly one must be able to perceive who has taken on a responsibility, succeeded or failed in performing a subtask, etc.), but the emphasis is on aspects of the situation that have consequences for how a group works toward a shared goal over time, rather than one person monitoring a complex information array and making real-time decisions. Researchers studying situation awareness have recognized the need to analyse and support the interdependencies of multiple operators (Salas et al., 1995; Endsley and Jones, 2001), but the research thus far has dealt primarily with individuals.

Part of the context surrounding a collaborative activity is the manner in which a shared activity is decomposed into smaller inter-related tasks, how these subtasks are assigned or adopted by collaborators, and when and how distributed subtasks are 
combined to achieve the higher-level goals. Although a rough framework for coordination may be negotiated early on in a collaborative activity, group members need to monitor this aspect of their shared context, as further roles are defined and assigned, priorities identified or modified, and so forth (Fig. 2). In the Virtual School, eighth and 12th grade students need to understand what their team members can and will contribute; they need to appreciate how various suggestions and requests might be heard by collaborators.

Activity awareness implies an awareness of other people's plans and understandings. Complex, long term, coordinated activity cannot succeed without on-going interpretation of current goals, accurate and continuing assessment of the current situation, and analysis and management of resources (including time) that constrain execution of possible plans. When goals and plans are shared or distributed, it is critical that all members of a team hold the same understanding of the goal and plans, and that they are aware also of how others on the team perceive the situation (Endsley, 1995; Hutchins, 1995).

Activities typically involve top-down goal decomposition (Sacerdoti, 1974), development and ordering of plan fragments (Sacerdoti, 1975), interleaving of planning, acting, and evaluation (Miller et al., 1960; Norman, 1986) and opportunistic plan revision (Hayes-Roth and Hayes-Roth, 1979; Suchman, 1986). Activity awareness implies knowledge of how task components are being identified, coordinated and carried out. Task components must be understood and pursued in the context of the overall purpose of a shared activity, the goals and requirements for completing it, and how individual tasks fit into the group's overall plan (Gutwin and Greenberg, 1996). In the Virtual School, groups of students need to understand how their piece of a project can contribute toward the whole endeavor.

This suggests that activity awareness is related to the concept of workflow (or project management; Flores et al., 1988; Ellis, 1999). A workflow system uses an expert-derived model of a business process to guide and monitor progress through a task. Task goals, task decomposition into subtasks, dependencies among tasks and subtasks, employee roles and assigned responsibilities, task and subtask completion status - all of these may be modeled in a workflow system. For highly scripted business processes, a workflow model can be quite effective in decomposing and tracking an extended activity (Prinz and Kolvenbach, 1996). However, workflow systems tend to break down in just the situations where activity awareness is most important-when opportunistic planning leads to creation or modification of goals or subgoals (HayesRoth and Hayes-Roth, 1979; Suchman, 1986; Abbot and Sarin, 1994). Our concept of activity awareness assumes that opportunistic planning and re-planning is common, even typical. Activity awareness depends on knowledge of what one's collaborators are doing, rather than what a symbolic model says they should be doing.

\section{Evaluating activity awareness factors in the virtual school}

Our analysis of awareness issues in the Virtual School was guided by a formative evaluation framework (Fig. 3) that considers how breakdowns in awareness might 


\begin{tabular}{|l|l|l|l|}
\hline \multicolumn{1}{|c|}{ Situation } & \multicolumn{1}{c|}{ Group } & \multicolumn{1}{c|}{ Task } & \multicolumn{1}{c|}{ Tools } \\
\hline $\begin{array}{l}\text { Classrooms } \\
\text { involved, teacher } \\
\text { commitment, } \\
\text { organizational } \\
\text { factors }\end{array}$ & $\begin{array}{l}\text { Demographics, } \\
\text { ages, domain } \\
\text { knowledge, } \\
\text { computer skill, } \\
\text { group size, group } \\
\text { dynamics }\end{array}$ & $\begin{array}{l}\text { Task models, type } \\
\text { of group activity, } \\
\text { activity duration, } \\
\text { task demands, }\end{array}$ & $\begin{array}{l}\text { System model, } \\
\text { integration } \\
\text { teols used, } \\
\text { equipment/software } \\
\text { reliability }\end{array}$ \\
& $\begin{array}{l}\text { demands, } \\
\text { communication } \\
\text { demands }\end{array}$ & \\
\hline
\end{tabular}

Fig. 3. Evaluation framework.

arise from several different perspectives (Urquijo et al., 1993; Charlton, 1996; Olson and Olson, 2001). This framework incorporates factors contributing to activity awareness, including the situation, group composition, the task and the tools provided in support of the task. This approach uses the group as the unit of analysis and provides a process-oriented framework for evaluating student interactions (Dillenbourg et al., 1996).

To illustrate how the collaborative situation, group, task and tools relate to one another, and how each contributed to awareness problems, we discuss a planning episode that culminated in a breakdown. This example-from an aerodynamics project in which middle and high school students built kites with different structural qualities - illustrates how the four factors described in Fig. 3 interrelate to produce awareness problems that undermine collaboration.

We were guided by the work of Neuwirth et al. (1998) in developing a coding system for analysis of the integrated event logs; the coding was done with QSR NVivo ${ }^{\circledR}$, a qualitative inquiry analysis package. In the analysis, we coded occurrence rather than frequency, because we were interested in a single planning breakdown and wanted to identify a breadth of contributory issues. This allowed us to use rich observational data to answer a practical research question-how did behavioral factors relating to our notification interfaces contribute to problems with activity awareness and collaborative work. This approach is appropriate for exploratory sequential data analysis (Sanderson and Fisher, 1994), where the focus is on hypothesis generation rather than hypothesis confirmation.

In this project, the groups met only once a week, so they typically planned the week by splitting work assignments between the two schools. There was a loose division of project work into subtasks, and a general agreement to have it completed by the next meeting, where the distributed group would collectively integrate their intermediate results using the Virtual School tools. In the example episode (next page), the students' plan consisted of an overall agreement to complete and post work by Thursday, in order to be able to collaborate synchronously on Friday.

High school student to middle school student: "Make sure that you have everything typed in by Thursday. We will too. In class on Friday, we can make the final changes.", 
Planning breakdown

The remote groups fail to achieve planning objectives and completed work. Contributing factors

1. Situation factors: Organizational factors related to teacher-teacher coordination

2. Group dynamics: Subgroup differences leading to group cohesion problems

3. Task factors: Tasks completed in a fragmented manner by proximal groups

4. Tools: Lack of tools to support evolution in planning and task representation

Fig. 4. Overview of planning breakdown and contributing factors.

This level of articulation in planning can be sufficient if the collaborators are disciplined, if their work context is well-structured, and if they have enough contact to support any more detailed coordination needs that arise. In this case, none of these conditions was true, and the plan failed. During the week, the members of each proximal subgroup encountered other tasks that competed for their time and attention. Neither subgroup completed the work they agreed to complete, nor did they notify the other group of the changes to their side of the plan. The consequence of this was that each subgroup felt the other had failed. Student interviews revealed that the groups were well-aware of their own efforts and the obstacles that had intervened, but to each subgroup it seemed that the other had just not bothered to meet their responsibilities. In the following sections, we examine in more detail the factors contributing to this breakdown (Fig. 4).

\subsection{Situational factors}

Over several months, the high school and middle school teachers had worked together to design the aerodynamics project. They specified deliverables and due dates, with the concept that the project would have identical requirements for the two classrooms. This is an extremely ambitious approach to cross-grade level collaboration. It is quite inconsistent with the solitary culture of public schools (Tyack and Cuban, 1995), and neither teacher had ever attempted or seen such an integrated classroom activity. Shortly into the project, circumstances specific to the different schools and classrooms began to impact the teachers' plan for how the project would proceed. An event at the high school, not taken into account during the original planning, led to an extension in the deadline for a component of the project for the high school subgroup. The high school students ignored their agreement to have work completed, believing that the middle school students' deadline had changed as well. In fact, the middle school teacher had not specified a hard deadline for this portion of the project, which is typical in managing the project work of younger students. As a result, the middle school students also failed to complete their part of the collaborative work by the agreed date.

Although teachers had agreed on dates and project assignments, when the actual schedule changed or softened, the teachers and their respective students did not notify their collaborators. With respect to the teachers, this can be understood in terms of workplace culture. Teachers typically work independently of other teachers 
and carry out their own curriculum, modulating it as necessary (Dunlap et al., 2000). These teachers had never before experienced a situation in which it was critical to apprise another teacher and his/her students - whom they had neither seen nor communicated with during the intervening time-of a change in schedule. In Winograd and Flores' (1986) sense (again drawing from Heidegger), the teachers were "thrown" into the context of their own pedagogical practices. They failed to appreciate that independent changes in the distributed contexts would lead to a lack of a shared understanding for interaction effects across the classrooms.

In a post-mortem discussion of the planning breakdown, a high school student asked her teacher about his role in group coordination.

High school student to teacher: "Why aren't you coordinating this with the other teacher? You're not keeping up with your responsibilities."

The student was joking with her teacher in this exchange, but she is also expressing frustration with the problems emerging due to the schedule misalignment. We frequently observed instances where lack of awareness of the remote group's situation led to conflicts, and it affected how well the groups ended up working together. The groups increasingly relied on each other less. Both groups continually expressed concern that the others were not contributing, and they failed to realize that their remote partners' circumstances produced valid reasons for not meeting the planned objectives. At a minimum, notifications could have informed the students of what was changing. This may in turn have prompted human-human communication to determine why the schedule had changed.

\subsection{Group factors}

Effective collaboration requires that co-workers trust one another to do their assigned jobs. Unfortunately, in the aerodynamics group, the high school students did not have complete confidence in their middle school partners.

High school teacher: "These high school kids are unwilling to really put themselves at "risk" by yielding power or something like power to the other kids. I'm not sure I think it is related to age. I've seen this kind of thing with the Aerodynamics group. There are two of everything, history, physics, bibliography, etc. They continue to see themselves as working in parallel with the other team, rather than together."

At the time of this comment, the two subgroups had begun to "play it safe". In effect, they created separate projects, duplicating rather than coordinating their efforts. In follow-up surveys and interviews, we found that middle school students were consistently more positive about the cross-age collaboration than their high school partners. We speculated that one cause for this is that the high school students are close to the end of their secondary school careers, and are much more aware of the importance of success in the sense of grade. The high school seniors in the aerodynamics group were taking the advance placement physics course, and were in the process of applying for university admissions. 
Furthermore, most of the high school students already had a substantial personal record of success in individual schoolwork. The cross-grade level collaboration created uncertainty; the middle school students were for the most part people they had never met before, whose most distinctive characteristic was that they were four years younger. Because the students did not have the normal social mechanisms for getting to know each other, they knew little of how the middle school students thought about the project, to what extent they were committed to succeeding, and so forth. This was reflected by the high school student's questions about the middle school students. In cases like these it is difficult for the groups to establish common ground, to develop and adjust predictions about their partners' goals, behaviors or strategies for task accomplishment.

The initial change in schedule and consequential separation of efforts was a selfreinforcing strategy. As more of the task components were duplicated in the two subgroups, planning and coordination with the remote partners became less relevant. As the misalignment became more severe, efforts to coordinate became correspondingly more difficult. The motivation for each subgroup to review and help develop the work of the other subgroup became smaller and smaller, with the result that there was little if any attempt to repair the collaboration breakdown. This was evident by the degree of shared work completed.

\subsection{Task factors}

Task components of individuals must be understood and pursued in the context of the group's overall purpose. This is only made possible with tight integration, communication and goal coordination. However, the two student groups approached their shared project differently, and this also contributed to the activity awareness breakdown. The eighth graders typically worked in class together on the project. Although they often did subdivide the work to some extent, they used class time to carry out focused collaborative work. The high school students rarely did project work during class, aside from meta-tasks like communicating and coordinating with proximal and remote group members. They used their class time primarily for socializing with each other. Tasks were subdivided between members and completed outside of class. Moreover, the high school students regularly missed group synchronous interactions due to a range of conflicting academic activities.

High school teacher: "Remember ... this is the group where two of the three high school kids are typically gone on Friday for academic competitions. Is it possible that the sporadic nature of the participation of the various high school kids could cause more confusion relating to what was said, agreed to, and decided?"

This led to a pattern of group interactions in which some members were sometimes or often missing. One group member would plan with the distributed group in the absence of his or her other proximal subgroup members, subsequently fail to communicate the plans with his or her subgroup, and then be absent the following week. As a result, the group would be in disagreement or confused about what was planned, or how things might have gone wrong at that subsequent meeting. We 
observed these conditions for more than $50 \%$ of the 26 weeks of collaboration. Students seemed to assume that no special procedures were needed to ensure that proximal group members would be notified about group decisions made in their absence. This may be due to the relatively frequent face-to-face interaction and casual checking-in that took place among the proximal subgroup members. However, it seemed that even this assumption was often wrong-the frequent face-to-face contact among proximal members was not enough to ensure that critical project-relevant information would be conveyed.

This problem was exacerbated by the fact that neither subgroup monitored who was representing the remote subgroup at any given time. They did not assign a person to the task; they casually shared the responsibility. During synchronous group interactions, different students typically took turns video conferencing or typing on the keyboard; it was often unclear who was actually present at the remote location. The video conferencing provided only a small view into the other classroom, and unidirectional microphones were used to limit ambient classroom noise, making it difficult to determine background conversations. Students often asked if others were present. The Virtual School has a mechanism for "group login", and the roster pane in the session manager displays who is present, but this appeared to be less salient to participants than the concrete view of collaborators seen in the video camera. When questioned about the problems, subgroups were not aware of how the process differences between the two groups were leading to awareness and planning breakdowns. They understood that there were problems, but they were unable to identify the source of the problems.

\subsection{Tool factors}

Activity awareness might have been better supported if the tools provided by the Virtual School had better matched the students' and teachers' expectations. For example, the log of actions maintained on the notice board (lower left of Fig. 1) was designed to be an awareness resource in the Virtual School. However, when we asked students about this tool, we found that they did not regularly use it. We speculated that the log was not salient to students because the teachers did not discuss how it might be used. Another contributing factor may have been that use of this tool often required students to change window focus, forcing them to leave their current work context.

Teachers also experienced problems in coordinating information. They would have liked to periodically check group progress against planned action items and deadlines. However, the project planning tool was a distinct notebook page, and planning entries were not automatically linked to the work addressing them (on other pages). Teachers had trouble with this.

High school teacher 1: "I've been in to look at these (notebooks) occasionally but haven't stayed organized well enough to use them effectively with students. Ideally the group would set their expected dates and then the teacher follows up to determine how they performed in meeting their own deadlines. This promotes 
group directed goals establishment and organization and allows an external check on progress. Intermediate steps are very important to preventing a last minute "all nighter" attempt at completion. It's just an administrative and records bear to do."

High school teacher 2: "I don't mean to be redundant but I still wish we had a place to list dates and what is due and then have a box or some place to check off that the work has been done. Ideally it would be nice to have the option built into each tab the students create so we wouldn't have to flip back and forth between what we are evaluating and the actual check off location. To be even more demanding I would like the program to be able to then "read" these boxes and maybe put them all on a separate page like a final rubric. I just don't want to have to go back and forth between say the research section and my rubric-it would be nice if the program could do that for me. Does that make any sense? I guess Ed's planner/calendar idea also supports this but I think I'm going a step beyond in asking for something that makes my work easier. The kids only have to keep up with one project and its progress but I have to monitor many!'

External representations of project work goals, state of collaborative artefacts, and planning become important when there are many interdependencies between situation factors, individual and group characteristics and task issues. It becomes even more important to externalize such information when group work is distributed in different sites and occurs at different times. In the Virtual School activities, notifications of changes to the situation, group or task were accomplished via channels used for the primary task (e.g. chat). As a result they competed with taskoriented interactions, and were often missed or ignored.

Many interaction resources are stripped away when collaboration takes place over computer-mediated channels. Our analysis of the planning breakdown points to some of the awareness problems that can arise when the normal mechanisms for establishing and maintaining common ground are compromised. We have shown how different aspects of the Virtual School activity context - the overarching framework for collaboration, how different constituents of the groups worked together and how they thought about their tasks, and how they used (or did not use) the tools available - combined to produce an activity awareness breakdown. In the balance of the paper, we consider how activity awareness can be better supported with notification design strategies.

\section{Notification system design strategies to support activity awareness}

Designing notification systems to address situational, group, task and tool breakdowns is a significant challenge. We believe that each of these four activity awareness factors can be supported by appropriate notification systems. We are currently redesigning the Virtual School software to incorporate such notification systems, both within the client software that students use on the desktop and on a large screen display that will be deployed in each classroom. Our strategies for this 
design effort are described below with respect to each of the factors identified in our breakdown analysis. We suggest that these redesign approaches can be extended to more broadly apply to notification systems supporting activity awareness for collaboration.

\subsection{Situational factors}

Many group breakdowns we observed resulted from inadequate situation awareness. Examples sometimes took the form of uncommunicated changes to externally defined parameters of the project, typically deadlines. Descriptions of deadlines and other project requirements were either not codified in any artefact shared by the group or existed only on notebook pages that users did not regularly consult or update. In these circumstances, coordination slips lead to goal failure. If events in the organizational context of a project can cause goal and plan modification for some team members, then all team members must be aware of the events.

We are pursuing several redesign approaches to remedy the communication of mutual context in the Virtual School notification interfaces. Many of the ideas we are developing involve providing graphical views of project timelines that include group deadlines and other potentially important scheduled class events which will serve as a situation status reminder. Fig. 5 shows a Virtual School interface designed for classroom-oriented, large-display devices (SMART Boards). Each of the four group timelines shows deadlines, communication and document revisions. Each group timeline is divided to distinguish subgroups. In Fig. 5, document and communication artefacts for a middle school subgroup's activity are shown on top, and corresponding icons for a high school subgroup are shown on the bottom. This display allows students and teachers to quickly glean an impression of group and subgroup activity in the context of all other activity. Detailed information about project artefacts, milestones, deadlines and so forth can be obtained by opening any of these displayed objects.

An animated information line (a "ticker"), at the top of the display, cycles through news items (documents recently created or saved by groups, changes to deadlines and so forth), providing minimally obtrusive updates. School-wide and class announcements can be presented in this display to broaden and strengthen shared context. This mechanism will support awareness of events that impact any of the collaborators (for example, teacher meetings or special student assemblies at one of the schools), and thereby help to explain and predict collaborators' behavior, promoting enhanced activity awareness.

\subsection{Group factors}

Breakdowns in group factors were caused by misperceptions of group member abilities, inadequate trust and non-collaborative patterns of goal-related activity. At the beginning of the projects, group members did not know much about their remote collaborators. Rather than working to better articulate their mutual understandings, 


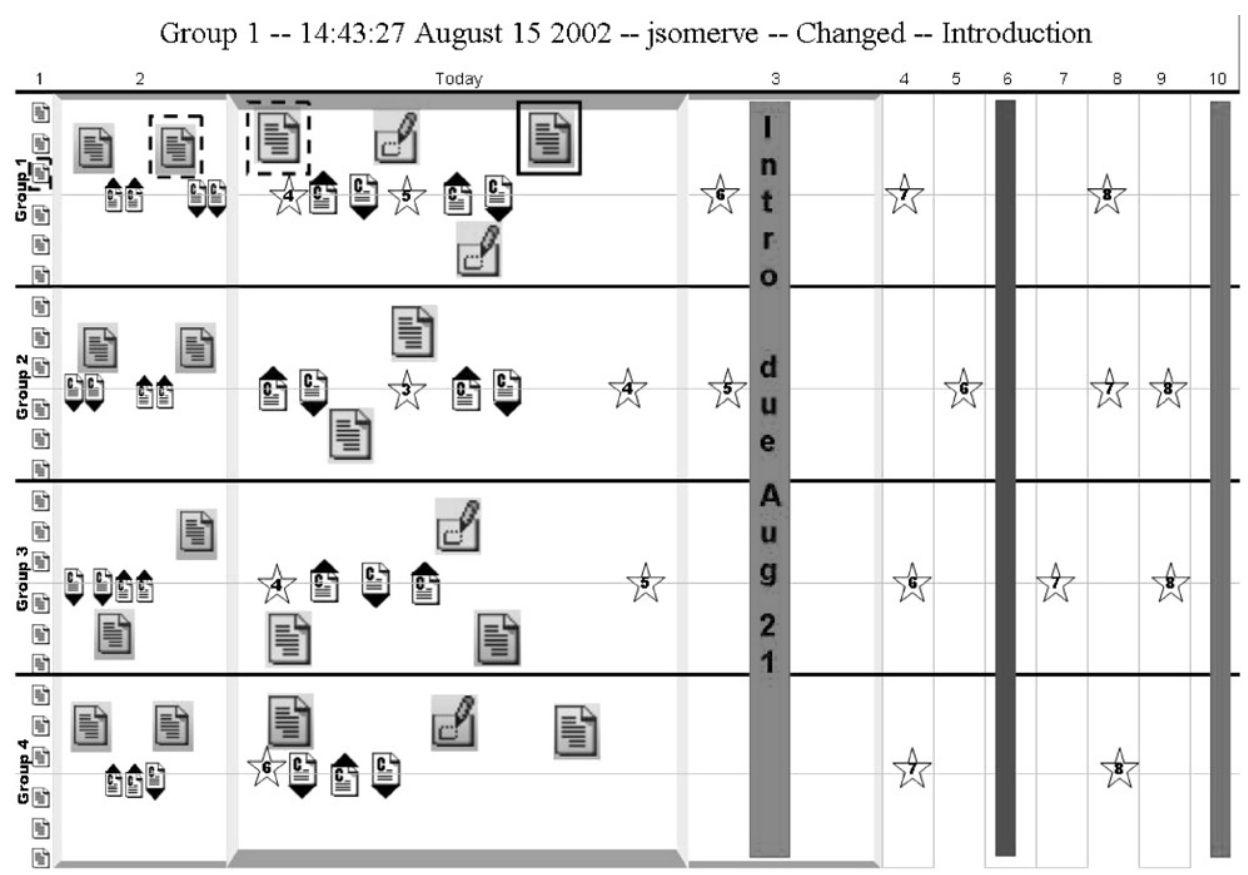

Fig. 5. Screenshot of a Virtual School notification interface designed for a large screen display. The interface summarizes the project situation by integrating project artefacts (document versions, images or chat sessions) with landmarks like progress milestones (stars) and deadlines (vertical bars) in a timeline.

they often relied on stereotypes, attributed any evidence of process loss to failings in their collaborators, and limited coordination and dependency in their work. An obvious approach to mitigating these problems is to provide mechanisms that allow collaborators to get to know more about one another more easily and to see contributions made by one another as the project progresses-as happens transparently in face-to-face collaboration. Methods for accomplishing this include an omnipresent chat area that provides easy and rapid access to remote group members, avatars that reflect the personality of their owners and integrated histories of all interactions. These interactions include chat logs, emails, project submissions and accesses (reads and writes) of shared documents. We incorporated these approaches in the Virtual School; in our redesign, we are further developing the third (integrated histories of interactions).

Fig. 6 shows a prototype of the redesigned Virtual School desktop client. This view shows a persistent user list and chat area, along with a shared desktop on which collaborative content can be edited. A group project timeline is incorporated as a peripheral visualization within the software the students will use on the desktop (corresponding to one row of the situation visualization in Fig. 5). Our hypothesis is that emphasizing project artefacts, and attributing work to subgroups will mitigate process loss, improve mutual understanding and facilitate the development of trust among collaborators. 


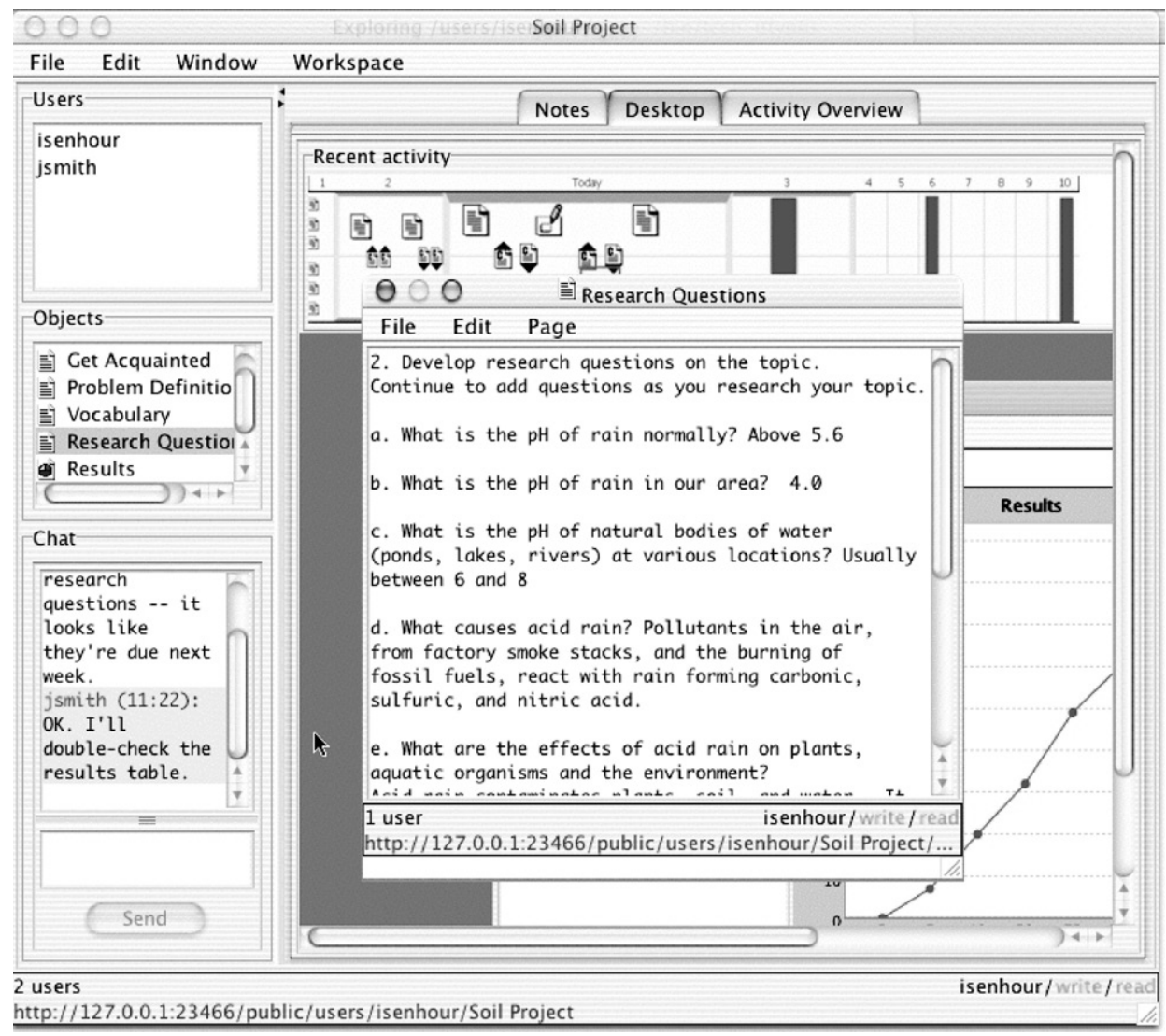

Fig. 6. Prototype of the Virtual School desktop client. The client includes omnipresent chat and user lists, as well as a group project timeline in the background of the shared desktop.

\subsection{Task factors}

The problematic task factors we observed are common to many examples of CSCW. Even when there was agreement about goals and plans, coordination tended to deteriorate over time. The majority of work was done asynchronously, with opportunities for synchronous interaction used primarily for coordination of nearfuture asynchronous work. The results of such synchronous interactions were not captured in revisions to explicit planning artefacts. For example, assignments of work to be done by the next synchronous meeting, intended to move the group's work toward a goal in the context of one or more deadlines, were often not captured and managed. In the Virtual School, this required switching to a different tool context, what Card and Henderson (1987) call a tool fault. More broadly, the benefits of maintaining explicit coordination artefacts are diffuse, and therefore difficult for any individual to justify (Grudin, 1994). Moreover, in many 
circumstances people do not like and cannot use overly explicit planning guidance (Suchman, 1986; Carroll, 1990).

Our approach to these issues in the new Virtual School prototype also leverages timeline views. Our prototype includes a document-oriented timeline view, illustrated in Fig. 7. This timeline provides a more detailed view of activity pertaining to a group's project artefacts. In this view, project artefacts are organized along the timeline's ordinate, presenting individual artefact histories (chat sessions, emails, document versions). This visualization provides a heuristic analysis of progress for each project artefact; for example, students can see at a glance that the Research Questions section has not been updated recently and may need to be revisited before the August 15 deadline. This design also addresses the needs of team members who miss a meeting or even a week: Members can use this view to examine recent project history at the level of changes to particular artefacts, and get caught up quickly. And it integrates a display of project history and status with access to project artefacts; all the chats, emails, document versions and deadlines can be opened in this display by

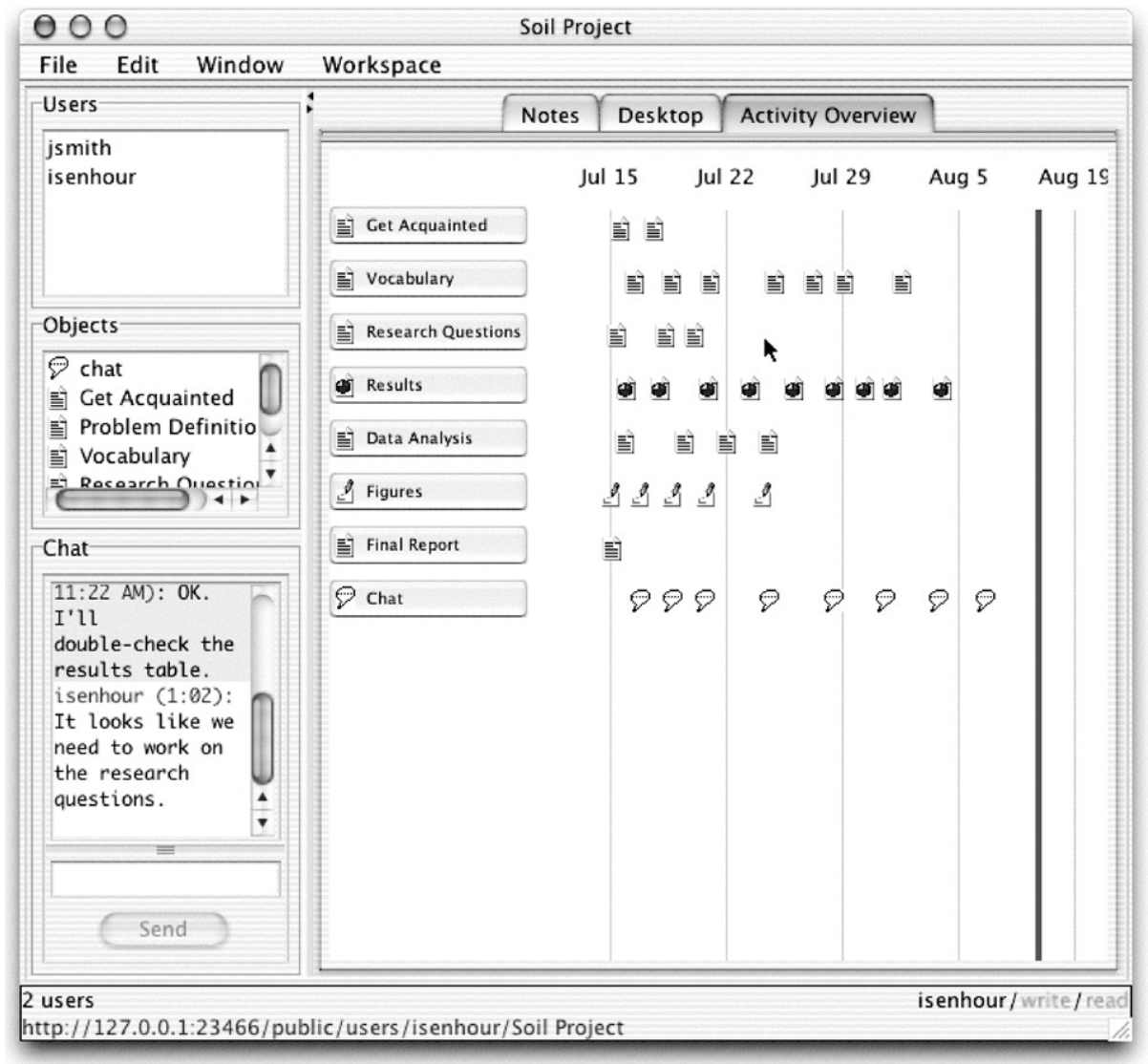

Fig. 7. Prototype document-oriented timeline view. 
point and click. Our hypothesis is that the less detailed views, in Figs. 5 and 6, will be useful for overall situation and group awareness at a glance, while the more detailed view will be useful for managing project tasks by describing specific document change histories.

\subsection{Tool factors}

The Virtual School evolved through several years of use and development. As various awareness and notification tools were added, the system model became more complex, as reflected in our breakdown study. For example, the notice board in the Virtual School actually is a timeline view, and thus anticipates a major theme in our redesign, but it displayed as a stand-alone window, and was often overlooked. The project planning tool was intended to address many of the problems we observed, but was not integrated with the users' work, and required extra tool switching steps to access.

Our approach is again to leverage project timelines to address these issues by better integrating our notification tools with the user's work. In our current prototype, we integrate the display of significant project artefacts and events with access controls for working with project artefacts. In this design, when users wonder whether a collaborator is available or whether an artefact has been recently changed, the information is available at a glance.

\section{Generalizing the design strategies}

Our evaluation of awareness and notifications in the Virtual School software, and our development of the concept of activity awareness as rationale for design changes suggest broader strategies for notification systems. At the most general level, the approach we are pursuing has two principles: First, we are trying to integrate notifications into the display and control of work objects. This approach contrasts with the strategy of placing notifications in the periphery of the display. Second, we are trying to leverage concrete and highly over-learned rubrics for organization and coordination of joint resources and interaction. In this paper, we have focused on time and timelines; elsewhere we have considered the rubrics of place, use and person (Carroll et al., 2003).

\subsection{Integration of notifications into the display and control of work objects}

In many circumstances, it is desirable to present notifications peripherally. In many cases, notifications are not task-related, and presenting them peripherally reduces the possibility that they will distract the user from a primary task. In the Virtual School, we encountered examples of a different sort. Notifications about the availability of a collaborator, or the versioning of a document section were sometimes not noticed. Collocating notifications with the work itself is a direct approach to this problem. More specifically, we hypothesize (1) that situation factors 
enable enhanced context when deadlines and external events are collocated with progress and planning representations, (2) group factors are improved when perception of group member abilities is more accurate, a result of the collocation of submission products, project milestones and collaborative communication, (3) task factors benefit from enhanced historical context and new abilities to associate and relate data from multiple sources, enabled by collocating a variety of artefacts and (4) tool factors such as the user's system model can be improved by collocation of information that will minimize tool switches and orient users to important information sources.

Integrating notifications into the display and control of work objects by collocation can entrain unwieldy visualizations. However, we feel that this is an area in which timelines provide much useful flexibility. The group-oriented timeline is compact enough to be included as a peripheral notification mechanism in the user interface that the students will use during work on a specific subtask, like document editing in Fig. 6, or to be employed in comparison of activity across several project groups, as in Fig. 5. But it directly leverages the more detailed timeline view that would be used for planning and initiating tasks, as in Fig. 7.

\subsection{Leverage concrete and highly over-learned rubrics for the organization and coordination of joint resources and interaction}

We have included two kinds of active timelines, each serving as both a data visualization and a data access mechanism. The group-oriented timeline emphasizes overall density of recent work activity with respect to groups and subgroups; the document-oriented timeline emphasizes more detailed patterns in activity at the level of specific document revisions and communications. The timelines are active, updating as project artefacts are modified and group members communicate.

The timeline representations provide an integrated view of the future (when things are due), the present (the current state of the groups' project artefacts) and the past (what has been completed), as suggested by one of our high school teacher collaborators. We hypothesize several specific advantages: (1) situational factors improve when a temporal representation of deadlines serves as a status reminder and prompts coordination activity, (2) group factors benefit from enhanced confidence in group members' abilities, which results from a historical record of trustworthiness, (3) since the timeline can also provide an information source that fills knowledge gaps about project progress, task factors are not impacted by changes in group leadership, student absenteeism and asynchronous project completion and (4) tool factors are enhanced by providing a relevant overview presentation of group progress that allows access to more detailed information.

Timelines as both visualizations and document access mechanisms have been implemented in a number of earlier systems. Lifestreams (Freeman and Gelernter, 1996) presents all of a user's documents and communications in a time-ordered view, with the capability of creating filtered "substreams" for more focused views of the document collection. The default Lifestreams view is ordinal, showing a stack of documents with the most recent at the top. LifeLines (Plaisant et al., 1996) and 
Virtual Communication Visualization (Beale et al., 2001) also provide time-based views of collections of heterogeneous data elements. These systems use an interval representation of time, with data representations placed along a linear time scale serving as indexes for detailed views. Focus + context techniques and subtimelines are used to manage scalability issues in large collections.

\section{Conclusions}

Through the last decade awareness has emerged as a major research area in $\mathrm{CSCW}$. More recently, notifications and notification systems have been delineated as a research focus in user interface design, but often limited to information and events peripheral to the user's primary task-oriented concerns. In this paper, we offered an analysis and an integration of these two areas, with a focus on identifying the key aspects of awareness in collaborative situations to understand usability problems and explore how notification systems can be better designed to support collaboration.

Collaborative awareness is frequently achieved by means of lightweight messaging tools and dynamic information displays that function as notification systems. For example, establishing and maintaining awareness of the presence of one's collaborators and their current actions is supported by notifications like buddy lists and radar views. Our particular interest is in understanding how notifications can support more complex and extended collaborations through activity awareness. Individuals who collaborate in a significant activity share goals, resources, deadlines, to-do items, social roles, work practices organizational culture and so forth. To coordinate this level of work effectively, they need to manage these artefacts; they need to be apprised of new versions and other changes, and they need to be supported in keeping track and integrating changes in individual artefacts over substantial spans of time.

We believe that supporting activity awareness is more than merely a matter of providing additional notifications. Messages indicating the creation of a new document version, the presence of a collaborator, or the receipt of a new email may not be noticed, or it may not be remembered when the information is critical. In our work, students did not use the log displayed in the Virtual School notice board, but it seems unlikely that the solution is to add more information to the log. Contrastingly, in maintaining activity awareness it is important to convey an understanding of the purpose and meaning of the information rather than just the information itself.

Many aspects of activity awareness are intentional in the sense that the information or event that collaborators need to become aware of is the state of someone else's mind. Direct approaches to supporting awareness of intentional states involve planning languages. The current wisdom in CSCW is that such approaches require a compelled discipline, and that even so, they generally fail. People, apparently, prefer to engage in planning more informally. It is difficult to motivate people to explicitly externalize and broadcast their goals and plans, and even when they do so, it is not always useful to or welcomed by their collaborators. 
We have developed an alternative approach in which generic data management activities incidentally support activity awareness. Live timelines provide data visualization and data access in the context of deadlines that emphasizes either group activity or patterns of activity within a set of documents. Common coordination elements (deadlines, communications and document versions) are pervasive across multiple notification mechanisms. Collocation of these elements within timeline views affords a meaningful summary of project progress; namely, the times of deadlines, communications and document versions; the relative locations of artefacts on the timeline with respect one another, and the change histories of project artefacts. Collocation of status views of multiple groups also affords plan revision by both students and teachers. We tried to place this work in a broader context of notifications for collaborative systems, suggesting two theses for further research, the integrating of notifications into the display and control of work activity, and the utility of concrete and over-learned rubrics for the organization and coordination of joint resources.

The relationship between the study of awareness factors and notification design is a mutually beneficial meeting ground for research interests in user interface displays and controls, on the one hand, and CSCW, on the other. As our conceptions of awareness broaden in their coverage of collaborative activities, notification systems can be better designed and evaluated. Investigations of activity awareness - and of notifications that can effectively support activity awareness - will be a particularly exciting and important facet of this joint endeavor.

\section{Acknowledgements}

We are grateful to Craig Ganoe, Jacob Somervell and Christa Chewar for their contributions to the prototype software described in Section 5. Our research on activity awareness is supported by the US National Science Foundation (NSF) Information Technology Research program (IIS 0113264), by A Research Assistance equipment grant from SMART Technologies Inc., and by the Office of Naval Research (N00014-00-1-0549). Our prior Learning in Networked Communities (LiNC) project was supported by NSF (REC-9554206) and by the Hitachi Foundation Information Technology in Education Initiative.

\section{References}

Abbot, K.R., Sarin, S.K., 1994. Experiences with workflow management: issues for the next generation. Proceedings of the Computer-Supported Cooperative Work: CSCW '94. ACM Press, New York, pp. 113-120.

Angiolillo, J.S., Blanchard, H.E., Israelski, E.W., 1993. Video telephone. AT\&T Technical Journal May-June, 7-20.

Bardram, J., 1998. Designing for the dynamics of cooperative work activities. In Proceedings of the ACM CSCW '98 Conference on Computer Supported Cooperative Work. Association for Computing Machinery, New York, pp. 89-98. 
Beacker, R., Nastos, D., Posner, I., Mawby, K. 1993. The user-centred iterative design of collaborative writing software. Proceedings of the INTERCHI' 93. ACM Press, New York, pp. 399-405.

Beale, M., McCrickard, S., North, C., Einstein, M., Saraiya, P., 2001. Visualizing communication timelines containing sparsely distributed clusters. In: Late Breaking Hot Topics Proceedings, IEEE InfoVis 2001 Symposium, Los Alamitos, California.

Begole, J., Rosson, M.B., Shaffer, C.A., 1999. Flexible collaboration transparency: supporting worker independence in replicated application-sharing systems. ACM Transactions on Computer-Human Interaction 6 (2), 95-132.

Blanchard, R.E., 1993. Situation awareness-transition from theory to practice. In: Proceedings of the Human Factors and Ergonomics Society 32nd Annual Meeting. Santa Human Factors and Ergonomics Society, Monica, CA, pp. 39-42.

Bodker, S., 1996. Applying activity theory to video analysis: how to make sense of video data in humancomputer interaction. In: Nardi, B.A. (Ed.), Context and Consciousness: Activity Theory and HumanComputer Interaction. MIT Press, Cambridge, MA, pp. 147-174.

Buxton, W.A.S., Sellen, A.J., Sheasby, M.C., 1997. Interfaces for multiparty video conferences. In: Finn, K.E., Sellen, A.J., Wilbur, S.B. (Eds.), Video-Mediated Communication. Lawrence Erlbaum Associates, Mahwah, NJ, pp. 385-400.

Cadiz, J.J., Venolia, G.D., Jancke, G., Gupta, A., 2001. Sideshow: providing peripheral awareness of important information. Microsoft Research Technical Report MSR-TR-2001-83, September 2001.

Card, S., Henderson, A., 1987. A mutliple, virtual-workspace interface to support user task switching. In: Proceedings of the ACM CHI/GI '87 Conference on Human Factors in Computing Systems and Graphics Interface. ACM, New York, pp. 53-59.

Carroll, J.M., 1990. The Nurnberg Funnel: Designing Minimalist Instruction for Practical Computer Skill. MIT Press, Cambridge, MA.

Carroll, J.M., Rosson, M.B., Neale, D.C., Isenhour, P.L., Dunlap, D., Ganoe, C.H., VanMetre, C., Seals, C., Fogarty, J., Schafer, Bussom, T., Bunn, K., Davie, P., Freeman, M., Goforth, A., Mauney, S., Rencsok, F., Anderson, C., Hertel, M., Svrcek, B., 2000a. The LiNC Project: learning in networked communities. Learning Technology, 2 (1) 20-24 (electronic publication at available at http:// lttf.ieee.org/learn_tech/issues/january2000/, ISSN 1438-0625).

Carroll, J.M., Chin, G., Rosson, M.B., Neale, D.C., 2000b. The development of cooperation: five years of participatory design in the Virtual School. In: Proceedings on Designing Interactive Systems: Processes, Practices, Methods, and Techniques. Association for Computing Machinery, New York, pp. 239-251.

Carroll, J.M., Rosson, M.B., Isenhour, P.L., Ganoe, C.H., Dunlap, D., Fogarty, J., Schafer, W., Van Metre, C., 2001. Designing our town: MOOsburg. International Journal of Human-Computer Studies $54,725-751$.

Carroll, J.M., Rosson, M.B., Dunlap, D.R., Isenhour, P.L., 2003. Frameworks for sharing knowledge: toward a professional language for teaching practices. Proceedings of the Hawaii International Conference on System Sciences; Mini-Track on Knowledge Management. IEEE Computer Society, Los Alamitos, California.

Charlton, S.G., 1996. SITE: an integrated approach to human factors testing. In: O'Brien, T.G., Charlton, S.G. (Eds.), Handbook of Human Factors Testing and Evaluation. Lawrence Erlbaum, Mahwah, NJ, pp. $27-40$.

Chi, E.H., Pirolli, P., Pitkow, J., 2001. The scent of a site: a system for analyzing and predicting information scent, usage, and usability of a site. Proceedings of the CHI 2001. ACM, New York, pp. 161-168.

Clark, H.H., 1996. Using Language. Cambridge University Press, New York.

Dillenbourg, P., Baker, M., Blaye, A., O'Malley, C., 1996. The evolution of research on collaborative learning. In: Spada, E., Reiman, P. (Eds.), Learning in Humans and Machine: Towards an Interdisciplinary Learning Science. Elsevier, Oxford, pp. 189-211.

Dourish, P., Bly, S., 1992. Portholes: supporting awareness in a distributed work group. In: Proceedings of the ACM CHI '92 Conference on Human Factors in Computing Systems. Association for Computing Machinery, New York, pp. 541-547. 
Dourish, P., Adler, A., Bellotti, V., Henderson, A., 1996. Your place or mine? learning from longterm use of audio-video communication. Computer-Supported Cooperative Work 5 (1), 33-62.

Dourish, P., Bentley, R., Jones, R., MacLean, A., 1999. Getting some perspective: using process descriptions to index document history. In: Proceedings of the ACM Conference on Supporting Group Work GROUP'99. ACM, New York.

Dunlap, D.R., Neale, D.C., Carroll, J.M., 2000. Teacher collaboration in networked communities (Special Issue on "On-Line Collaborative Learning Environments"). Educational Technology and Society 3(3), http://ifets.ieee.org/periodical/

Egido, C., 1988. Video-conferencing as a technology to support group work: a review of its failures. In: Proceedings of the ACM CSCW '88 Conference on Computer Supported Cooperative Work. Association for Computing Machinery, New York, pp. 13-24.

Ellis, C., 1999. Workflow technology. In: Beaudouin-Lafon, M. (Ed.), Computer Supported Cooperative Work. Wiley, Chichester, UK, pp. 29-54.

Endsley, M.R., 1988. Design and evaluation for situation awareness enhancement. In: Proceedings of the Human Factors Society 32nd Annual Meeting. Human Factors Society, Santa Monica, CA, pp. $97-101$.

Endsley, M.R., 1995. Toward a theory of situation awareness in dynamic systems. Human Factors 37 (1), $32-64$.

Endsley, M.R., 2000. Theoretical underpinnings of situation awareness: a critical review. In: Endsley, M.R., Garland, D.J. (Eds.), Situation Awareness Analysis and Measurement. Lawrence Erlbaum, Mahwah, NJ, pp. 3-32.

Endsley, M., Jones, W.M., 2001. A model of inter- and intrateam situational awareness: implications for design, training, and measurement. In: McNeese, M., Salas, E., Endsley, M. (Eds.), New Trends in Cooperative Activities: Understanding System Dynamics in Complex Environments. Human Factors and Ergonomics Society, Santa Monica, CA, pp. 46-67.

Erickson, T., Smith, D.N., Kellogg, W.A., Laff, M.R., Richards, J.T., Bradner, E., 1999. Socially translucent systems: social proxies, persistent conversation, and the design of Babble. In: Proceedings of CHI'99, Pittsburgh, PA.

Fish, R.S., Kraut, R.E., Root, R.W., Rice, R.E., 1993. Video as a technology for informal communication. Communications of the ACM 36 (1), 48-61.

Flores, F., Graves, M., Hartfield, B., Winograd, T., 1988. Computer systems, the design of organizational interaction. ACM Transactions on Office Information Systems 6 (2), 153-172.

Freeman, E., Gelernter, D., 1996. Lifestreams: a storage model for personal data (ACM special interest group on management of data). SIGMOD Record 25 (1), 80-86.

Fussell, S.R., Kraut, R.E., Lerch, F.J., Scherlis, W.L., McNally, M.M., Cadiz, J.J., 1998. Coordination, overload and team performance: effects of team communication strategies. In: Proceedings of the ACM CSCW ' 98 Conference on Computer Supported Cooperative Work. Association for Computing Machinery, New York, pp. 275-284.

Gibson, S., Neale, D.C., Carroll, J.M., VanMetre, C.A., 1999. Mentoring in a school environment. In: Proceedings of the CSCL '99: Computer Supported Cooperative Learning. Lawrence Erlbaum, Mahwah, NJ, pp. 182-188.

Grudin, J., 1994. Groupware and social dynamics: eight challenges for developers. Communications of the ACM 37 (1), 92-105.

Greenberg, S., 1996. Peepholes: low cost awareness of one's community. Conference Companion of CHI 1996, pp. 206-207.

Gutwin, C., 2002. Traces: visualizing the immediate past to improve group interaction. In: Proceedings of the Conference on Human-Computer Interaction and Computer Graphics (Graphics Interface '02). Morgan Kaufman, San Francisco, pp. 43-50. Available at http://hci.usask.ca/publications/2002/ traces-gi/traces.pdf

Gutwin, C., Greenberg, S., 1996. Workspace awareness for groupware. In: Proceedings of the ACM CHI '96 Conference on Human Factors in Computing Systems (Companion). Association for Computing Machinery, New York, pp. 208-209. 
Gutwin, C., Greenberg, S., 1998a. Effects of awareness support on groupware usability. In: Proceedings of the ACM CHI '98 Conference on Human Factors in Computing Systems. Association for Computing Machinery, New York, pp. 511-518.

Gutwin, C., Greenberg, S., 1998b. Designing for individuals, design for groups: tradeoffs between power and workspace awareness. In: Proceedings of the ACM CSCW '98 Conference on Computer Supported Cooperative Work. Association for Computing Machinery, New York, pp. 207-216.

Gutwin, C., Greenberg, S., 2000. The effects of workspace awareness support on the usability of real-time distributed groupware. ACM Transactions on Computer-Human Interaction, in press.

Gutwin, C., Roseman, M., Greenberg, S., 1996. A usability study of awareness widgets in a shared workspace groupware system. In: Proceedings of the ACM CSCW '96 Conference on Computer Supported Cooperative Work. Association for Computing Machinery, New York, pp. 258-267.

Hall, R.W., Mathur, A., Jahanian, F., Prakash, A., Rassmussen, C., 1996. Corona: a communication service for scalable, reliable group collaboration systems. In: Proceedings of the ACM CSCW '96 Conference on Computer Supported Cooperative Work. Association for Computing Machinery, New York, pp. 140-149.

Hartswood, M., Procter, R., 2000. Design guidelines for dealing with breakdowns and repairs in collaborative work settings. International Journal of Human-Computer Studies 53, 91-120.

Hawryszkiewyez, I.T., Gorton, I., Fung, L., 1995. Maintaining awareness in tightly coordinated asynchronous groups. In: Proceedings of the OZCHI'95, CHISIG, Australia, Downer, ACT, pp. $152-156$.

Hayes-Roth, B., Hayes-Roth, F., 1979. A cognitive model of planning. Cognitive Science 3, 275-310.

Hill, W.C., Hollan, J.D., Wroblewski, D., McCandless, T. 1992. Edit wear and read wear. Proceedings of the CHI '92 Conference on Human Factors in Computing Systems. ACM, New York, pp. 3-9.

Hutchins, E., 1995. Cognition in the Wild. MIT Press, Cambridge, MA.

Isenhour, P.L., Carroll, J.M., Neale, D.C., Rosson, M.B., Dunlap, D.R., 2000. The Virtual School: an integrated collaborative environment for the classroom (special issue on "On-Line Collaborative Learning Environments"). Educational Technology and Society 3(3), http://ifets.ieee.org/periodical/

Ishii, H., Kobayashi, M., Arita, K., 1994. Iterative design of seamless collaboration media. Communications of the ACM 37 (8), 83-97.

Jermann, P., Soller, A., Muehlenbrock, M., 2002. From mirorring to guiding: a review of state of the art technology for supporting learning. CSCL'02, Boulder, CO, pp. 324-331.

Malone, T.W., Crowston, K., 2001. The interdisciplinary study of coordination. In: Olson, G.M., Malone, T.W., Smith, J.B. (Eds.), Coordination Theory and Collaboration Technology. Lawrence Erlbaum Associate, Hillsdale, NJ, pp. 7-49.

Mantei, M.M., Baecker, R.M., Sellen, A., Buxton, W.A.S., Milligan, T., Wellman, B., 1991. Experiences in the use of a media space. In: Proceedings of the ACM CHI '91 Conference on Human Factors in Computing System. Association for Computing Machinery, New York, pp. 203-208.

Masoodian, M., Apperley, M., Frederickson, L., 1995. Video support for shared workspace interaction: an empirical study. Interacting with Computers 7, 237-253.

Miller, G.A., Galanter, E., Pribam, K., 1960. Plans and the Structure of Behavior. Rinehart \& Winston, New York, Holt.

Neale, D.C., Carroll, J.M., 1999. Multi-faceted evaluation for complex, distributed activities. In: Proceedings of the CSCL'99 Computer Supported Cooperative Learning. Lawrence Erlbaum, Mahwah, NJ, pp. 425-433.

Neale, D.C., Dunlap, D.R., Isenhour, P., Carroll, J.M., 2000. Collaborative critical incident development. In: Proceedings of the 44th Annual Meeting of the Human Factors and Ergonomics Society. Human Factors and Ergonomics Society, Santa Monica, CA, pp. 598-601.

Neale, D.C., Dunlap, D.R., Isenhour, P.L., Rosson, M.B., Carroll, J.M. Collaborative breakdowns in the Virtual School, in preparation.

Neuwirth, C.M., Morris, J.H., Regli, S.H., Chandhok, R., Wenger, G.C. 1998. Envisioning communication: task-tailorable representations of communication in asynchronous work. In: Proceedings of the ACM CSCW '98 Conference on Computer Supported Cooperative Work. Association for Computing Machinery, New York, pp. 265-274. 
Norman, D.A., 1986. Cognitive engineering. In: Norman, D.A., Draper, S. (Eds.), User Centered System Design: New Perspectives on Human-Computer Interaction. Lawrence Erlbaum Associates, Hillsdale, NJ.

Olson, M.H., Bly, S.A., 1991. The Portland experience: a report on a distributed research group. International Journal of Man-Machine Studies 34, 211-228.

Olson, G.M., Olson, J.S., 2001. Technology support for collaborative workgroups. In: Olson, G.M., Malone, T.W., Smith, J.B. (Eds.), Coordination Theory and Collaboration Technology. Lawrence Erlbaum, Mahwah, NJ, pp. 559-23584.

Olson, G.M., Olson, J.S., 2002. Distance matters. In: Carroll, J.M. (Ed.), Human-Computer Interaction in the New Millennium. Addison-Wesley, Boston.

Plaisant, C., Milash, B., Rose, A., Widoff, S., Shneiderman, B., 1996. LifeLines: visualizing personal histories. In: Proceedings of the ACM CHI '96 Conference on Human Factors in Computing Systems. ACM, New York, pp. 221-227.

Prinz, W., Kolvenbach, S., 1996. Support for workflows in a ministerial environment. In: Ackerman, M. (Ed.), CSCW '96: Proceedings of the Conference on Computer Supported Cooperative Work. ACM, New York, pp. 199-208.

Sacerdoti, E.D., 1974. Planning in a hierarchy of abstraction spaces. Artificial Intelligence 5, 115-135.

Sacerdoti, E.D., 1975. The nonlinear nature of plans. Proceeedings of the Fourth International Joint Conference on Artificial Intelligence, Menlo Park, CA, pp. 206-214.

Salas, E., Prince, C., Baker, D.P., Shrestha, L., 1995. Situation awareness in team performance: implications for measurement and training. Human Factors 37 (1), 123-136.

Sanderson, P.M., Fisher, C., 1994. Exploratory sequential data analysis: foundations. Human-Computer Interaction 9, 251-317.

Smith, R.B., 1992. What you see is what I think you see. SIGCUE Outlook 21 (3), 18-23.

Smith, R.B., Hixon, R., Horan, B., 1998. Supporting flexible roles in a shared space. In: Proceedings of the ACM CSCW '98 Conference on Computer Supported Cooperative Work. Association for Computing Machinery, New York, pp. 197-206.

Suchman, L.A., 1986. Plans and Situated Actions. Cambridge University Press, New York.

Tang, J.C., 1991. Findings from observational studies of collaborative work. International Journal of Man-Machine Studies 34, 143-160.

Tang, J.C., Isaacs, E.A., 1993. Why do users like video? Computer Supported Cooperative Work 1, 163-196.

Tang, J.C., Isaacs, E.A., Rua, M., 1994. Supporting distributed groups with a montage of lightweight interactions. In: Proceedings of the ACM CSCW '94 Conference on Computer Supported Cooperative Work. Association for Computing Machinery, New York, pp. 23-33.

Tang, J., Yankelovich, N., Begole, J., Van Kleek, M., Li, F., Bhalodia, J., 2001. ConNexus to awarenex: extending awareness to mobile users. Proceedings of the CHI 2001, Seattle, WA, March 31-April 5, 2001.

Tyack, D., Cuban, L., 1995. Tinkering Toward Utopia: A Century of Public School Reform. Harvard University Press, Cambridge, MA.

Urquijo, S.P., Scrivener, S.A.R., Palmen, H.K., 1993. The use of breakdown analysis in synchronous CSCW system design. In: Proceedings of the European Conference on Computer-Supported Cooperative Work. Kluwer Academic Publishers, Boston, pp. 281-293.

Viegas, F.B., Donath, J.S., 1999. Chat circles. Proceedings of the CHI '99 Conference on Human Factors in Computing Systems. ACM, New York, pp. 9-16.

Wexelblat, A., Maes, P., 1999. History-rich tools for information foraging. Proceedings of the CHI '99 Conference on Human Factors in Computing Systems. ACM, New York, pp. 270-277.

Whittaker, S., O'Conaill, B., 1997. The role of vision in face-to-face and mediated communication. In: Finn, K.E., Sellen, A.J., Wilbur, S.B. (Eds.), Video-Mediated Communication. Lawrence Erlbaum Associates, Mahwah, NJ, pp. 23-49.

Winograd, T., Flores, F., 1986. Understanding Computers and Cognition: A New Foundation for Design. Ablex, Norwood, NJ. 